\title{
Penile Portion of the Urethra
}

National Cancer Institute

\section{Source}

National Cancer Institute. Penile Portion of the Urethra. NCI Thesaurus. Code C61123.

The portion of the urethra that spans the corpus spongiosum. 